\title{
Addendum to the paper: Proteoglycans support proper granule formation in pancreatic $A R 42 J$ cells
}

\author{
Miguel Aroso $^{1} \cdot$ Brigitte Agricola $^{2}$ - Christian Hacker ${ }^{3}$ Michael Schrader ${ }^{1,3}$
}

Published online: 11 June 2016

(C) Springer-Verlag Berlin Heidelberg 2016

Addendum to: Histochem Cell Biol (2015)

144(4):331-36

DOI: $10.1007 / \mathbf{s 0 0 4 1 8 - 0 1 5 - 1 3 3 9 - x}$

The original method established for estimating the granule size distribution is published in Hacker C, Asadi J, Pliotas C, Ferguson S, Sherry L et al. (2016). Nanoparticle suspensions enclosed in methylcellulose: a new approach for quantifying nanoparticles in transmission electron microscopy. Sci Rep 6:25275.

Michael Schrader

m.schrader@exeter.ac.uk

1 Centre for Cell Biology and Department of Biology,

University of Aveiro, Campus Universitário de Santiago,

3810-193 Aveiro, Portugal

2 Department of Cell Biology and Cell Pathology, University of Marburg, 35037 Marburg, Germany

3 College of Life and Environmental Sciences, Biosciences, University of Exeter, Geoffrey Pope Building, Stocker Road, Exeter EX4 4QD, UK 